2012-07

\title{
Global habitat suitability of cold-water octocorals
}

\author{
Yesson, C
}

http://hdl.handle.net/10026.1/1321

10.1111/j.1365-2699.2011.02681.x

Journal of Biogeography

Wiley

All content in PEARL is protected by copyright law. Author manuscripts are made available in accordance with publisher policies. Please cite only the published version using the details provided on the item record or document. In the absence of an open licence (e.g. Creative Commons), permissions for further reuse of content should be sought from the publisher or author. 


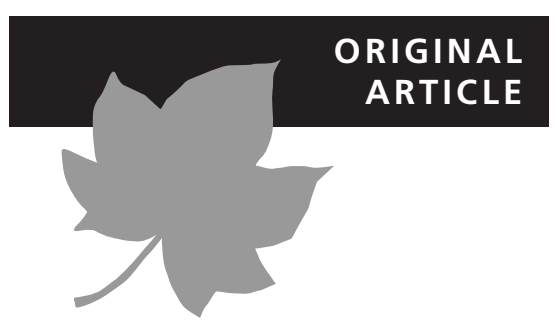

\section{Global habitat suitability of cold-water octocorals}

Chris Yesson ${ }^{1 \star}$, Michelle L. Taylor ${ }^{2}$, Derek P. Tittensor ${ }^{3,4}$, Andrew J. Davies ${ }^{5}$, John Guinotte ${ }^{6}$, Amy Baco ${ }^{7}$, Julie Black ${ }^{8}$, Jason M. Hall-Spencer ${ }^{9}$ and

Alex D. Rogers ${ }^{2}$

${ }^{1}$ Institute of Zoology, Zoological Society of London, Regent's Park, London NW1 4RY, UK, ${ }^{2}$ Department of Zoology, University of Oxford, Tinbergen Building, South Parks Road, Oxford, OX1 3PS, UK, ${ }^{3}$ United Nations Environment Programme World Conservation Monitoring Centre, Cambridge, CB3 ODL, UK, ${ }^{4}$ Microsoft Research Computational Science Laboratory, Cambridge, CB3 OFB, UK, ${ }^{5}$ School of Ocean Sciences, Bangor University, Menai Bridge, LL59 5AB, Wales, UK, ${ }^{6}$ Marine Conservation Institute, 2122 112th Avenue NE, Suite B-300, Bellevue, WA 98004-2947, USA, ${ }^{7}$ Department of Earth, Ocean and Atmospheric Sciences, Florida State University, Tallahassee, FL 32306-4320, USA, ${ }^{8}$ Marine Special Protection Areas team, JNCC Support Co, Inverdee House, Baxter Street, Aberdeen, AB11 9QA, Scotland, UK, ${ }^{9}$ Marine Biology and Ecology Research Centre, University of Plymouth, Drake Circus, Plymouth, PL4 8AA, UK

${ }^{\star}$ Correspondence: Chris Yesson, Institute of Zoology, Zoological Society of London, Regent's Park, London NW1 4RY, UK.

E-mail: chris.yesson@ioz.ac.uk.

\section{ABSTRACT}

Aim Three-quarters of Octocorallia species are found in deep waters. These coldwater octocoral colonies can form a major constituent of structurally complex habitats. The global distribution and the habitat requirements of deep-sea octocorals are poorly understood given the expense and difficulties of sampling at depth. Habitat suitability models are useful tools to extrapolate distributions and provide an understanding of ecological requirements. Here, we present global habitat suitability models and distribution maps for seven suborders of Octocorallia: Alcyoniina, Calcaxonia, Holaxonia, Scleraxonia, Sessiliflorae, Stolonifera and Subselliflorae.

\section{Location Global.}

Methods We use maximum entropy modelling to predict octocoral distribution using a database of 12,508 geolocated octocoral specimens and 32 environmental grids resampled to 30 arc-second (approximately $1 \mathrm{~km}^{2}$ ) resolution. Additionally, a meta-analysis determined habitat preferences and niche overlap between the different suborders of octocorals.

Results Suborder Sessiliflorae had the widest potential habitat range, but all records for all suborders implied a habitat preference for continental shelves and margins, particularly the North and West Atlantic and Western Pacific Rim. Temperature, salinity, broad scale slope, productivity, oxygen and calcite saturation state were identified as important factors for determining habitat suitability. Less than $3 \%$ of octocoral records were found in waters undersaturated for calcite, but this result is affected by a shallow-water sampling bias.

Main conclusions The logistical difficulties, expense and vast areas associated with deep-sea sampling leads to a gap in the knowledge of faunal distributions that is difficult to fill without predictive modelling. Global distribution estimates are presented, highlighting many suitable areas which have yet to be studied. We suggest that approximately $17 \%$ of oceans are suitable for at least one suborder but $3.5 \%$ may be suitable for all seven. This is the first global habitat suitability modelling study on the distribution of octocorals and forms a useful resource for researchers, managers and conservationists.

\section{Keywords}

Calcite saturation state, conservation biogeography, habitat suitability modelling, marine conservation, Maxent, niche, Octocorallia, predictive modelling, vulnerable marine ecosystems. 


\section{INTRODUCTION}

Octocorallia are the most diverse group of corals, with over 3000 described species (Cairns, 2007). Approximately 75\% of octocorals are found in waters deeper than $50 \mathrm{~m}$, a lower proportion than azooxanthellate Scleractinia (87\%; Roberts et al., 2009). Cold-water octocorals are not reef-forming but they can form single- or multi-species assemblages where the density of colonies on the seabed is very high. These are commonly referred to as 'coral gardens' or 'coral forests' (Freiwald et al., 2004; Stone, 2006). These communities can be composed of Octocorallia, Anthipatharia, Scleractinia and Stylasteridae, creating structural habitat that can be exploited by other fauna. The entire emergent epibenthic community can reach up to $100 \%$ coverage of the seabed, with coral colony densities as high as $6.52 \mathrm{~m}^{-2}$ in waters off Alaska (Stone, 2006). The entire epibenthos can attain several metres in height and form a significant heterogeneous habitat (Freiwald et al., 2004; Stone, 2006).

Habitats formed by cold-water corals have a high biological diversity, especially in terms of the species richness of associated animals (Stone, 2006; Edinger et al., 2007). The relationship between corals and other fauna is difficult to ascertain because many species use coral facultatively and are often found in alternative habitats (e.g. Edinger et al., 2007). However, some studies indicate the importance of octocoral habitats for organisms such as invertebrates (Buhl-Mortensen \& Mortensen, 2004), groundfish (Edinger et al., 2007), commercial rockfish (Stone, 2006) and general fish associations with a variety of coral habitats (Söffker et al., 2011). One clear indication of the association of octocorals and commercial fish species is the frequency of occurrence of octocorals as by-catch in most types of bottom contact gear used by fisheries (Stone, 2006). Bottom-trawling in particular has the capacity to devastate cold-water coral frameworks by entirely removing structural habitats and associated sessile fauna (Watling \& Norse, 1998; Hall-Spencer et al., 2002; Freiwald et al., 2004), but the majority of impact studies have focused on scleractinian corals. Fishing impacts on octocorals are less well known, although observations from the north-western Atlantic and north-eastern Pacific indicate that they are also vulnerable (Stone, 2006; Edinger et al., 2007). The resilience of such communities is perceived to be very low as some octocorals have slow growth rates and high longevity (Freiwald et al., 2004; Althaus et al., 2009). To date, there have been no quantitative studies on the recovery of cold-water octocoral communities that are known to have been destroyed by fishing activity. The limited observations that do exist are based on broader cold-water coral communities and suggest that no or very limited recolonization occurs several decades after impact (Althaus et al., 2009). Concerns over these long-lasting impacts have led to a number of resolutions by the United Nations General Assembly (UNGA) relating to the protection of vulnerable marine ecosystems (VMEs) in the oceans from fisheries, culminating in UNGA Resolutions 61/105 and 64/72 (Rogers \& Gianni, 2010), which enshrine a precautionary approach to fishing in areas where VMEs occur by requiring impact assessment of bottom fishing activities. However, problems with the implementation of these rules have been identified and more precautionary measures have been recommended (Auster et al., 2011).

A significant problem with the identification of VMEs, such as octocoral habitat, is the lack of information on the geographic distribution of benthic communities throughout much of the deep sea. The deep ocean is the most poorly sampled habitat on Earth and patterns of diversity and distribution of the majority of species remain largely unresolved (Glover \& Smith, 2003). Several approaches, singly or in combination, have been used to identify where VME species occur or are likely to occur including: (1) historical observations of species, (2) the use of fisheries observers to collate bycatch information on species found in VMEs, (3) multibeam and single-beam bathymetric surveys to identify small-scale changes in bathymetry, slope angle and backscatter associated with some VMEs (e.g. scleractinian reefs), (4) surveys using a remote operated vehicle (ROV), submersibles or other sampling methods, and (5) habitat suitability modelling. The advantage of habitat suitability models is the potential to predict distributions in areas where no direct specimen observations have occurred.

Habitat suitability modelling has been applied to the prediction of the distribution of cold-water corals at local, regional and global scales (Leverette \& Metaxas, 2005; Bryan \& Metaxas, 2006, 2007; Davies et al., 2008; Dolan et al., 2008; Tittensor et al., 2009; Woodby et al., 2009; Davies \& Guinotte, 2011). These studies, with the exception of Woodby et al. (2009), have all employed statistical methods that are based on presence-only data. Reliable absence data for deep-sea species generally is not available as only a tiny proportion of habitats are usually sampled and there are large mismatches between patchy habitats and analysis resolutions. For Scleractinia, environmental niche factor analysis (ENFA) and maximum entropy (Maxent) models have been employed at both the species level, for Lophelia pertusa, a major reef-forming coldwater coral (Davies et al., 2008), for framework-forming scleractinians (Davies \& Guinotte, 2011) and for all coldwater scleractinians occurring on seamounts (Tittensor et al., 2009). These studies identified aragonite saturation state, temperature, salinity and oxygen concentrations as being important influences on the distribution of framework-forming cold-water scleractinian corals. These studies predicted that the North East Atlantic, south-eastern coast of USA and New Zealand are important areas for framework-forming coldwater scleractinian corals in terms of providing suitable habitat. The seamount study also identified a band of suitable habitat in the Southern Hemisphere ranging from around $20^{\circ}$ to $50^{\circ} \mathrm{S}$, spanning the Atlantic, Indian and Pacific oceans (Tittensor et al., 2009); presumably because it included many species for which the geographic range was not principally restricted to, or centred outside of, the North Atlantic Ocean.

Habitat suitability analyses have only been carried out on octocorals at the regional scale, in the north-eastern Pacific 
(Bryan \& Metaxas, 2006) and north-western Atlantic (Leverette \& Metaxas, 2005). These studies concentrated on 13 species of corals belonging to the families Paragorgiidae and Primnoidae and results suggested that depth, slope, temperature and surface chlorophyll $a$ concentrations were important predictors of coral distribution, with some differences between taxa. These studies were criticized for being inconsistent with observations that gorgonians were broadly distributed in continental-shelf environments, probably because the resolution was too coarse, and because of a lack of in situ observations and verification (Etnoyer \& Morgan, 2007).

Woodby et al. (2009) analysed the distribution of octocorals, scleractinians and stylasterids, although the majority of corals observed were octocorals. They used a different modelling approach, where video transect data were used to generate predictive models of coral presence and absence using logistic regression and generalized estimating equations. These predictions were based upon a limited number of physical parameters (depth, slope and rugosity of the seabed) derived from multibeam echosounder data. This limited the scope of the predictions as it didn't include information on temperature, salinity, oxygen or carbonate chemistry that is available from global datasets, although the importance of these variables at local scales is currently unclear. Depth and slope were identified as particularly important for predicting coral distribution in the Aleutian region (Woodby et al., 2009).

Our study used 32 environmental variables spanning all factors previously recognized as potentially influencing coral distribution, at a very high global resolution of 30-arc seconds (approximately $1 \mathrm{~km}^{2}$ ) that were developed by Davies \& Guinotte (2011). Maps of predicted habitat suitability are provided for seven octocoral suborders, with the aims of providing further information on where coral-associated VMEs are likely to occur and of identifying the environmental variables that could play an important role in controlling their distribution.

\section{MATERIALS AND METHODS}

\section{Octocoral distribution data}

Octocoral distribution data were gathered from museum collections, cruise reports, deep-sea researchers, oceanographic institutions and publications to form a single database. A total of 85 separate data sources were used: 21 institutes/museums/ online databases/individual researchers, and 64 original journal/report sources. A data cleaning and filtering process was used to remove records of poor quality or outside the remit of this study. We set a threshold of $50 \mathrm{~m}$ water depth based on the specimen collection data to separate deep/cold-water from shallow-water octocorals, reflecting the tendency for zooxanthellate species to occur in waters shallower than $50 \mathrm{~m}$ and azooxanthellate species in waters $>50 \mathrm{~m}$ depth (Cairns, 2007). The majority of records came from trawl sampling gear where the location and depth were noted at the beginning and end of each haul. For octocoral records collected from such hauls the positional midpoint was used. As trawl records introduce spatial uncertainty to the model predictions, this will only affect the analysis where the beginning and end points cross a pixel boundary of the underlying environmental data and there is a large environmental difference between these locations. Taxonomic names were reconciled with the taxonomic treatment of Williams and Cairns (http://researcharchive.calacademy. org/research/izg/OCTOCLASS.htm), with those names not found in this treatment excluded from the analysis. Duplicate records found in multiple museum collections or publications were removed. A total of 12,508 observations of octocorals were collected, spanning seven suborders within Octocorallia (see Table 1 for a taxonomic breakdown by suborder and family). Because of the present lack of agreement and knowledge on octocoral taxonomy at fine taxonomic resolutions, any analysis below the level of suborder would be insufficiently robust for some families, genera and species; hence, analyses were performed at the suborder level only. See Appendix S1 in Supporting Information for details of the sources of the distribution data. Prior to analysis multiple records that fell within a single grid cell were removed, retaining only a single record to ensure that each 30 -arc second cell was represented by only a single specimen for each suborder (Table 1).

\section{Environmental layers}

An ever-increasing array of global marine environmental data are becoming publicly available, many of which are potentially useful for habitat suitability modelling. This study focused on the 32 environmental layers outlined in Table 2. The majority of these three-dimensional environmental datasets are a series of vertically stratified grids of relatively coarse resolution $\left(0.25-3.6^{\circ}\right.$, the majority were $\left.1^{\circ}\right)$, whilst the highest resolution data was the 30 -arc second bathymetric grid. Ideally, habitat suitability modelling should be conducted at the finest possible resolution, in order to resolve local-scale patterns. To achieve a fine resolution, we used a recent interpolation of these data to 30 arc-second seafloor grids (Davies \& Guinotte, 2011), which were shown to correlate well with water bottle data (e.g. temperature correlation of 0.924 ).

The selection of environmental layers is a critical step in preparation for habitat suitability modelling because many modelling techniques are adversely affected by incorporating too many variables, potentially causing over-fitting of the model (Peterson et al., 2007). One approach is to pre-select a smaller subset of available variables for use in the final model based on biological knowledge or single-factor analyses (e.g. Peterson et al., 2007). Many of the layers examined for this study were similar in nature (e.g. co-variant measures of productivity including the vertically generalized production model and particulate organic carbon) and can be grouped together as aspects of biology, chemistry or geology (see Table 2). The groups chosen were 'bathymetry': layers directly derived from the bathymetry grid; 'carbonate chemistry': measures of aragonite and calcite saturation states; 
Table 1 Summary of data for Octocorallia used in this study. Only records identified to suborder were used for the analysis. Family names are given where 50 or more samples are given. Within each suborder only a single observation of presence per 30 -arc second grid square was retained for the analysis.

\begin{tabular}{|c|c|c|c|}
\hline Suborder & Family & Total & $\begin{array}{l}\text { Retained } \\
\text { for analysis }\end{array}$ \\
\hline \multirow[t]{4}{*}{ Alcyoniina } & Alcyoniidae & 516 & \\
\hline & Nephtheidae & 465 & \\
\hline & Nidaliidae & 214 & \\
\hline & three others & 9 & \\
\hline Alcyoniina Total & & 1204 & 618 \\
\hline \multirow[t]{5}{*}{ Calcaxonia } & Chrysogorgiidae & 554 & \\
\hline & Ellisellidae & 623 & \\
\hline & Isididae & 1567 & \\
\hline & Primnoidae & 2604 & \\
\hline & three others & 6 & \\
\hline Calcaxonia Total & & 5354 & 2060 \\
\hline \multirow[t]{4}{*}{ Holaxonia } & Acanthogorgiidae & 507 & \\
\hline & Gorgoniidae & 272 & \\
\hline & Keroeididae & 104 & \\
\hline & Plexauridae & 1762 & \\
\hline Holaxonia Total & & 2645 & 1021 \\
\hline \multirow[t]{5}{*}{ Scleraxonia } & Anthothelidae & 384 & \\
\hline & Coralliidae & 288 & \\
\hline & Melithaeidae & 53 & \\
\hline & Paragorgiidae & 279 & \\
\hline & three others & 53 & \\
\hline Scleraxonia Total & & 1057 & 560 \\
\hline \multirow[t]{6}{*}{ Sessiliflorae } & Anthoptilidae & 114 & \\
\hline & Funiculinidae & 143 & \\
\hline & Kophobelemnidae & 154 & \\
\hline & Protoptilidae & 97 & \\
\hline & Umbellulidae & 426 & \\
\hline & others & 6 & \\
\hline Sessiliflorae Total & & 940 & 589 \\
\hline \multirow[t]{2}{*}{ Stolonifera } & Clavulariidae & 400 & \\
\hline & two others & 2 & \\
\hline Stolonifera Total & & 402 & 216 \\
\hline \multirow[t]{3}{*}{ Subselliflorae } & Halipteridae & 58 & \\
\hline & Pennatulidae & 414 & \\
\hline & Virgulariidae & 275 & \\
\hline Subselliflorae Total & & 747 & 436 \\
\hline $\begin{array}{l}\text { Others (indeterminate } \\
\text { suborder) }\end{array}$ & & 159 & 0 \\
\hline Total & & 12,508 & 5500 \\
\hline
\end{tabular}

'hydrodynamics': measures of local current flow; 'productivity': direct and indirect measures of primary productivity; 'oxygen': a variety of measurements of oxygen dissolution/saturation/ utilization; 'chemistry': all other chemical measurements of the water column; 'temperature': the single measurement of temperature. Temperature was not grouped with other variables, as it is important in the regulation of biological processes and high temperatures can trigger coral diseases (Rogers et al., in press) and along with salinity is the most frequently sampled environmental parameter of the water column.
Table 2 List of environmental variables used in studies on the global distribution of deep-sea octocorals and the references for these data. See Davies \& Guinotte (2011) for full details of layers.

\begin{tabular}{|c|c|}
\hline Variable (abbreviation) & Source \\
\hline \multicolumn{2}{|l|}{ Bathymetry variables } \\
\hline Depth (depth) & Becker et al. (2009) \\
\hline Slope (slope) & Becker \& Sandwell (2008) \\
\hline Rugosity ${ }^{1,3}$ slope $^{2,3}$ & $\begin{array}{l}\text { Derived from } \\
\text { Becker et al. (2009) }\end{array}$ \\
\hline \multicolumn{2}{|l|}{ Carbonate chemistry variables } \\
\hline $\begin{array}{l}\text { Aragonite (arag) and calcite (calc) } \\
\text { saturation horizons }\end{array}$ & Steinacher et al. $(2009)^{\star, 5}$ \\
\hline $\begin{array}{l}\text { Aragonite (arago) and calcite } \\
\text { (calco) saturation horizons }\end{array}$ & Orr et al. $(2005)^{\star, 6}$ \\
\hline \multicolumn{2}{|l|}{ Chemical variables } \\
\hline $\begin{array}{l}\text { Alkalinity (alk), Carbonate ion } \\
\text { concentration (cion), Dissolved } \\
\text { inorganic carbon (dic) }\end{array}$ & Steinacher et al. $(2009)^{*, 5}$ \\
\hline $\begin{array}{l}\text { Nitrate (nit), phosphate (phos), } \\
\text { silicate (sil) }\end{array}$ & Garcia et al. $(2006 b)^{*}$ \\
\hline $\mathrm{pH}(\mathrm{ph})$ & Steinacher et al. $(2009)^{\star, 5}$ \\
\hline pH (pho) & Orr et al. $(2005)^{\star, 6}$ \\
\hline Salinity (sal) & Boyer et al. $(2005)^{*}$ \\
\hline \multicolumn{2}{|l|}{ Hydrodynamic variables } \\
\hline $\begin{array}{l}\text { Regional current flow (regfl), } \\
\text { Vertical flow (vertfl) }\end{array}$ & Carton et al. (2005) $\uparrow^{4}$ \\
\hline \multicolumn{2}{|l|}{ Oxygen variables } \\
\hline $\begin{array}{l}\text { Apparent oxygen utilization } \\
\text { (aoxu), Dissolved oxygen } \\
\text { (diso2), Percentage oxygen } \\
\text { saturation (poxs) }\end{array}$ & Garcia et al. (2006a)* \\
\hline \multicolumn{2}{|l|}{ Biological productivity variables } \\
\hline Particulate organic carbon (poc) & Lutz et al. (2007) \\
\hline Primary productivity (modis) & MODIS L3 Annual SMI ${ }^{7}$ \\
\hline $\begin{array}{l}\text { Primary productivity export } \\
\text { (vgpm) }\end{array}$ & $\begin{array}{l}\text { Behrenfeld \& Falkowski } \\
(1997)^{8}\end{array}$ \\
\hline \multicolumn{2}{|l|}{ Other variables } \\
\hline Temperature (temp) & Boyer et al. $(2005)^{*}$ \\
\hline
\end{tabular}

*Available in 33 z-layers ranging from 0 to $5500 \mathrm{~m}$.

$\uparrow$ Available in 40 z-layers ranging from $0-5375 \mathrm{~m}$.

${ }^{1}$ Derived using Bathymetric Terrain Modeler. ${ }^{2}$ Derived using ArcGIS spatial analyst. ${ }^{3}$ Four layers created using moving windows of 5, 20, 30 and $100 \mathrm{~km}$. Slope abbreviations (slo5 km, slo20 km, slo30 km, slo100 km); rugosity abbreviations (rug5 km, rug20 km, rug30 km, rug100 km). ${ }^{4}$ Simple Ocean Data Assimilation (SODA) model 2.0.4; mean 1990-2007. ${ }^{5}$ Extracted from SRES B1 scenario model; mean 2000-2009. ${ }^{6}$ Extracted from the Ocean-Carbon Cycle Model Intercomparison Project Phase 2 (OCMIP2) model data for 1995. ${ }^{7}$ Downloaded from http://oceancolor.gsfc.nasa.gov, Moderate Resolution Imaging Spectroradiometer (MODIS) L3 product; mean 20022008. ${ }^{8}$ Standard Vertically Generalized Production Model (VGPM) using MODIS data; mean 2002-2007.

A correlation analysis of environmental layers at locations with coral observations was performed using the Pearson correlation with the 'cor' function in the stats package of $\mathrm{R}$ (version 2.11.1, http://www.R-project.org/). Many variables showed high correlation with other variables (Appendix S2a), 
notably amongst aragonite and calcite saturation states (correlation $>0.91$ ), and oxygen measurements $(>0.81)$ with intermediate correlation for productivity measurements (> 0.5). The depth layer was not included in the final analyses, as all layers utilized depth at some point in their construction. A single variable from each of the aforementioned variable groups was selected for each model in order to represent a wide range of potentially important biological factors, but to reduce the potential for model over-fitting. The variable selection in each group was based on the predictive value of habitat suitability models based on a single environmental layer.

\section{Modelling methods}

We used MAXENT version 3.2.1 (http://www.cs.princeton.edu/ $\sim$ schapire/maxent/) to generate the models. The Maxent algorithm estimates habitat suitability by finding the distribution with maximum entropy under constraints given the relationship of environmental data with species presence data. Tittensor et al. (2009) found that the maximum entropy method consistently outperformed ENFA in cross-validation of models for cold-water corals. In this study, 10,000 points were randomly selected to use as background data to construct the model, and each model run set aside $30 \%$ of occurrence records for model evaluation. Maxent model parameters used were regularization multiplier $=1$, maximum iterations $=500$ and a convergence threshold $=10^{-5}$. Initially, Maxent models were run using a single environmental layer as input, to test for the fit of the validation points to individual layers. This was assessed using the AUC (area under the receiver operating characteristic curve; Fielding \& Bell, 1997) to select those layers that best explained the distribution of each taxon. The AUC is a threshold independent measure of model performance ranging from 0 to 1 . An AUC value of 0.5 represents a model that performs no better than random, whilst 1 is maximally predictive. The final models were created using seven environmental layers, the single most explanatory layer from each group outlined above (i.e. one oxygen measure, one productivity measure etc.). Map outputs were based on models using all occurrence data for training, and saved as logistic scores (01 ), which represent the probability of presence of the modelled taxa (Phillips \& Dudík, 2008). A consensus/summary map incorporating all seven octocoral suborders was constructed by generating binary presence/absence maps from the model outputs indicating areas of high suitability using a score threshold that maximized the sum of the specificity and sensitivity based on the validation data (Carroll, 2010). These binary layers were summed to generate a layer containing the number of octocoral suborders predicted to be present per cell. The use of thresholds to convert multi-score predictions into binary presence/absence is a simplification that masks important detail of relative preference, but can provide useful summaries for conservation planning (Carroll, 2010).

Several tests were performed to examine the impact of sampling bias in the distribution data. Sampling bias in occurrence data is likely to be both geographic, towards more accessible locations closer to industrialized locations, and bathymetric, with shallower sampling being more prevalent due to the logistics and expense of sampling at depth. To test for this, models were run excluding data from well-sampled areas. Also, Phillips et al. (2009) suggest a method to correct for sampling bias, by selecting background data with similar sampling bias as the occurrence data. To test for depth bias random background data were chosen to match the depth distribution profile of the occurrence data based on the 33 depth bins used by the underlying global environmental grids (i.e. the World Ocean Atlas; Boyer et al., 2005; Garcia et al., 2006a,b). Models were re-run using this depth-biased background data.

Additional models were also run using the ecological niche factor analysis (ENFA; Hirzel et al., 2002) approach, to test the sensitivity of results to the model algorithm used. ENFA models were run using OPENMODELLER version 1.1.0 (http:// openmodeller.sourceforge.net/) using the default settings. AUC values for single and multi-variable models were tested for significant differences using the statistic of DeLong et al. (1988) with the R package pROC (http://expasy.org/tools/ $\mathrm{pROC} /$ ). Similarity of model projections was assessed using the I statistic of niche correlation (Warren et al., 2008) in the $\mathrm{R}$ package phyloclim (http://cran.r-project.org/web/packages/ phyloclim/).

\section{RESULTS}

The octocoral database contained 12,508 samples (Fig. 1). After removing records without order-level identification and those outside the area with environmental data, 5500 remained for modelling. More than half of the observations were collected in the North Atlantic. In contrast, only $6 \%$ of samples are from the Indian Ocean, indicating significant sampling bias around developed countries. Frequency distribution profiles showed that sampling was also skewed towards shallower areas (selected variables in Fig. 2 and the complete dataset in Appendix S2b).

AUC values for each of the 32 single-variable models for each suborder are shown in Table 3. The AUC values ranged from almost indistinguishable from random (0.565, Sessiliflorae - slope $30 \mathrm{~km}$ radius) up to a high of 0.960 (Subselliflorae - temperature). Of the two hydrodynamics variables, the models based on regional current flow consistently outperformed those based on vertical flow. Similarly, models solely based on particulate organic carbon flux outperformed all other models within the productivity group for every suborder. There was variation in AUC values between suborders, but in every group there was one variable that outperformed the others. Apparent oxygen utilization was the most explanatory for six of the seven suborders within the oxygen derived variables. Of variables derived solely from bathymetry data, the coarse slope layer (slopes over a $100 \mathrm{~km}$ radius) had the highest predictive values for six of the seven suborders. Similarly, salinity was most predictive for six of the seven suborders within the chemistry-derived variables. Two datasets 


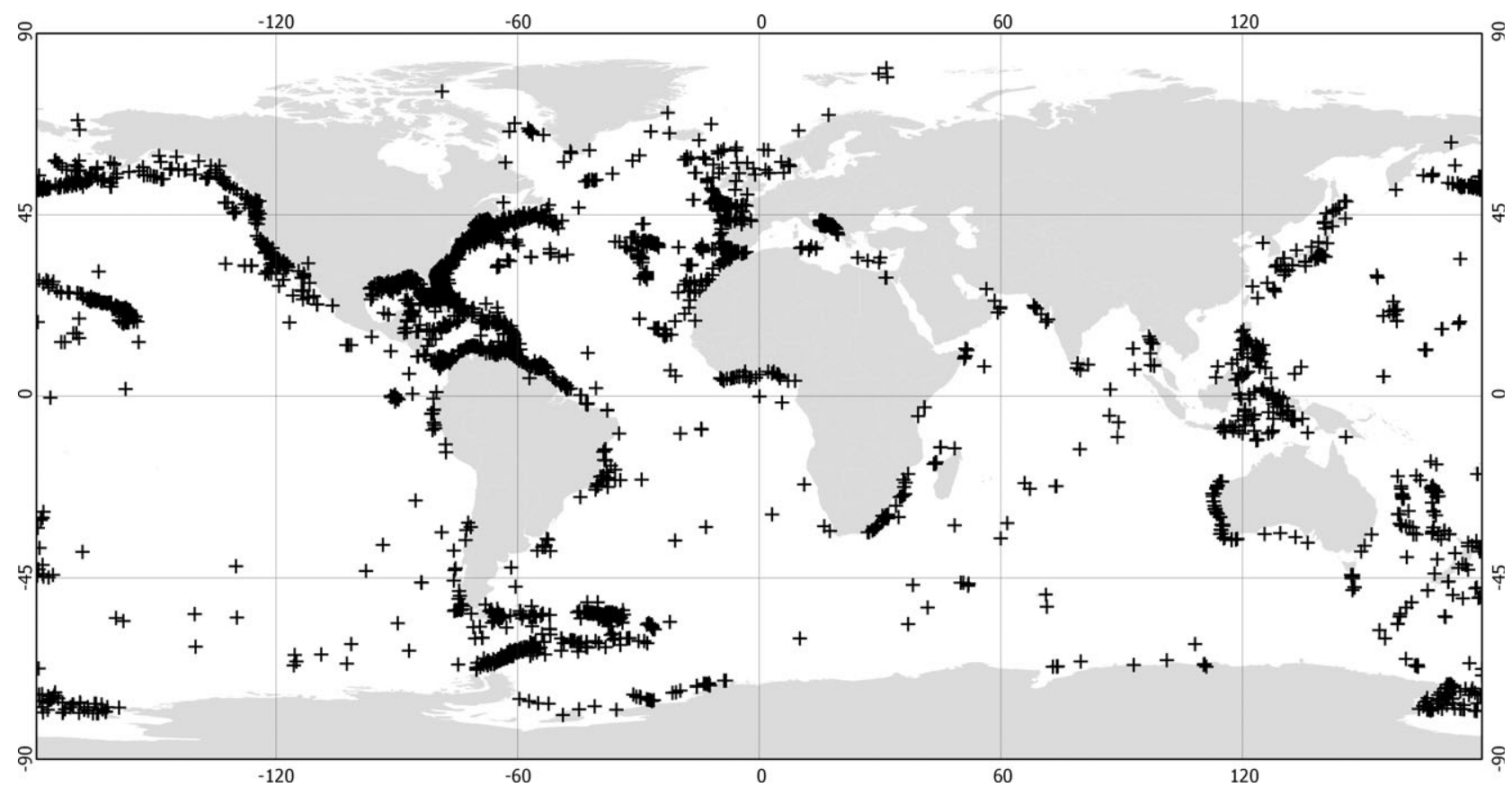

Figure 1 Global distribution of deep-sea octocoral observations based on the database of 12,508 samples.

for both aragonite and calcite saturation states were available for analysis (Orr et al., 2005; Steinacher et al., 2009). Models based on data from Steinacher et al. (2009) performed consistently better for all taxa, with AUC values ranging from 0.887 to 0.958 . AUC values for models based on aragonite saturation state differed by less than 0.001 from those based on calcite saturation. These differences were always assessed as insignificant by the DeLong et al. (1988) method. However, the calcite saturation state variable was selected as it was marginally better for four of the seven suborders.

The seven selected environmental variables were used to build a final multi-layer model for each taxon (Table 4 shows model evaluation, including AUC values, for these models). All multivariate models were significantly better than any single-variable model, as assessed by the DeLong statistic. AUC values ranged from 0.945 (Sessiliflorae) up to 0.981 (Stolonifera). Variable contributions for the models show the predominance of calcite saturation state in determining habitat suitability for suborders of Alcyonacea. For the suborders of Pennatulacea it is temperature that contributes most to the models, but the relative contributions of other variables (productivity, salinity and calcite saturation state) are noteworthy.

All suborders show a preference for continental shelves and continental margins, particularly for the North and West Atlantic and the Western Pacific Rim (Fig. 3). The MidAtlantic Ridge is highlighted in all maps, along with many smaller topographic features in the high seas. The consensus map shows that approximately $17 \%$ of global oceans are suitable for at least a single octocoral suborder, and that 3.5\% of the ocean area is suitable for all seven suborders.
The results from the ENFA analyses highlighted the same broad-scale topographic features such as continental shelves and the Mid-Atlantic Ridge. Appendix S3 provides full details of the ENFA model results for each suborder. ENFA models performed significantly worse than Maxent models (as assessed by AUC), which is consistent with prior analyses comparing the two approaches in the deep sea (Tittensor et al., 2009).

Forty-six per cent of distribution data came from the FAO areas of the NW Atlantic and Western Central Atlantic, an area representing only c. $6 \%$ of global oceans. In order to test for a regional bias in the construction of the habitat suitability models, additional Maxent models were built without data from these two areas. These model outputs were found to be highly correlated with models constructed with all available data points. The mean $I$ statistic for the seven suborders was 0.87 , with a minimum of 0.75 for Alcyoniina and a maximum of 0.93 for Calcaxonia, AUC values ranged from 0.898 to 0.982 , but DeLong significance tests were not possible due to the reduced sample numbers used in the revised models.

Although only $6 \%$ of octocoral observations originated from the Indian Ocean, there were extensive areas of suitable habitat predicted by the models that have not yet been sampled, including sections of the ocean ridges. Many locally important areas are difficult to see on the global maps (Fig. 3), but the high resolution of the models enables zooming to reveal rich detail. For example, within the approximately $545,000 \mathrm{~km}^{2}$ Exclusive Economic Zone of the British Indian Ocean Territory, which has been declared a Marine Protected Area by the British government, our analysis suggests that more than $65,000 \mathrm{~km}^{2}$ is suitable (based on the binary threshold) for at 

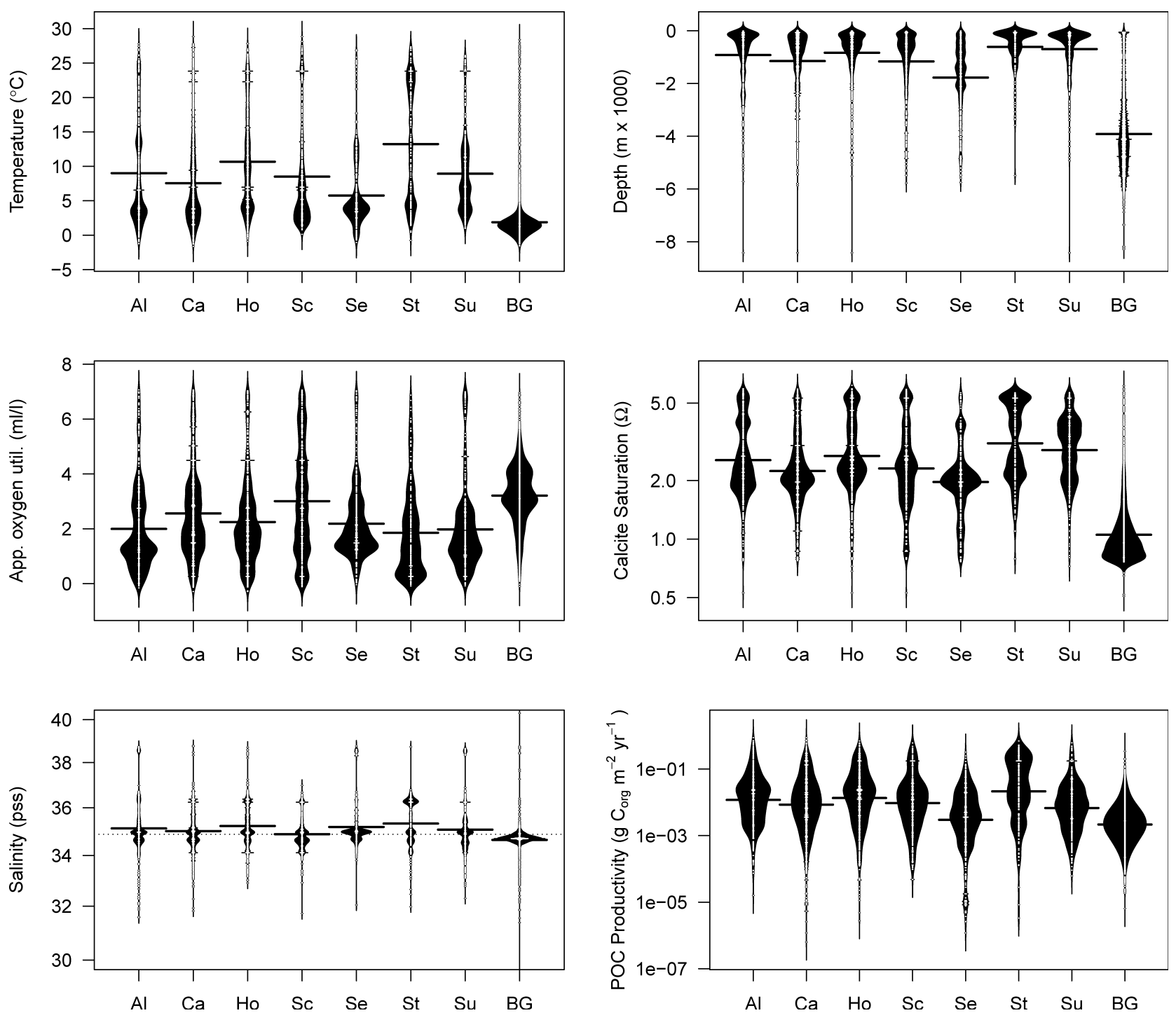

Figure 2 Bean plots showing frequency distribution profiles for selected environmental variables at locations with deep-sea octocoral observations. Al, Alcyoniina; Ca, Calcaxonia; Ho, Holaxonia; Sc, Scleraxonia; Se, Sessiliflorae; St, Stolonifera; Su, Subselliflorae; BG, global background based on a random sample of 5000 points. Black 'beans' represent frequency distribution profiles, wider sections indicate higher sample density, black horizontal bars show suborder means. Calcite and POC productivity refer to the calco and poc measures of Table 2, respectively. App. oxygen util. $=$ apparent oxygen utilization.

least one suborder of octocorals, and just under $10,000 \mathrm{~km}^{2}$ is suitable for all suborders (Fig. 4). To date, no deep water surveys have been conducted in this area and no observations were available for the database or validation.

\section{DISCUSSION}

\section{Assessing octocoral habitat preferences}

Thirty-two environmental variables were tested for their relationship with the distribution of octocorals. The carbonate chemistry variables calcite and aragonite saturation state were amongst the best performing for single-variable models and weighted heavily in the marginality of the ENFA models.
Although the relative importance of aragonite and calcite may vary among taxa, octocorals do require an accessible source of calcium carbonate for their structural development (Bayer \& Macintyre, 2001). Calcite is essential in the skeletal structure of octocorals, as the free or fused plates, sclerites, that are embedded in the mesenchyme provide overall support for colonies as well as for specific structures such as polyps (Bayer \& Macintyre, 2001; Millero, 2006). The variable of calcite saturation state was the major contributing factor determining the final model for all Alcyonacea suborders and the second most important factor for Pennatulacea suborders, although there is a risk of overinterpretation of the reported variable contributions given the intercorrelation of all environmental variables. 
Table 3 Test AUC values for Maxent models of the global distribution of deep-sea octocorals based on a single variable. Variable names in bold indicate those chosen for final models. The highest value in each column is shown in bold, with highest values within each variable group underlined. The final model used the seven variables highlighted with bold text. The proportion of global ocean area with suitable habitat used the threshold that maximizes the sum of specificity and sensitivity.

\begin{tabular}{|c|c|c|c|c|c|c|c|c|}
\hline Group & Variable & Alcyoniina & Calcaxonia & Holaxonia & Scleraxonia & Sessiliflorae & Stolonifera & Subselliflorae \\
\hline \multirow[t]{10}{*}{ Bathymetry } & depth & 0.935 & 0.914 & 0.940 & 0.923 & 0.870 & 0.949 & 0.947 \\
\hline & $\operatorname{rug} 100 \mathrm{~km}$ & 0.763 & $\underline{0.814}$ & 0.820 & 0.790 & 0.762 & 0.782 & 0.725 \\
\hline & $\operatorname{rug} 20 \mathrm{~km}$ & 0.596 & 0.729 & 0.688 & 0.719 & 0.663 & 0.606 & 0.573 \\
\hline & $\operatorname{rug} 30 \mathrm{~km}$ & 0.612 & 0.688 & 0.682 & 0.745 & 0.584 & 0.642 & 0.662 \\
\hline & $\operatorname{rug} 5 \mathrm{~km}$ & 0.613 & 0.682 & 0.666 & 0.748 & 0.570 & 0.638 & 0.657 \\
\hline & slo100 km & 0.772 & 0.813 & 0.820 & 0.790 & 0.763 & 0.782 & 0.800 \\
\hline & slo20 km & 0.605 & 0.727 & 0.695 & 0.718 & 0.660 & 0.589 & 0.683 \\
\hline & slo30 km & 0.627 & 0.673 & 0.676 & 0.728 & 0.565 & 0.641 & 0.648 \\
\hline & slo5 km & 0.605 & 0.677 & 0.684 & 0.730 & 0.569 & 0.608 & 0.660 \\
\hline & slope & 0.651 & 0.590 & 0.611 & 0.686 & 0.608 & 0.604 & 0.639 \\
\hline \multirow[t]{4}{*}{ Carbonate chemistry } & arag & 0.934 & 0.906 & $\underline{0.942}$ & 0.913 & $\underline{0.888}$ & 0.958 & 0.953 \\
\hline & arago & 0.914 & 0.875 & 0.913 & 0.853 & 0.878 & 0.925 & 0.931 \\
\hline & calc & 0.934 & 0.907 & 0.941 & 0.914 & 0.887 & 0.958 & 0.952 \\
\hline & calco & 0.915 & 0.880 & 0.912 & 0.863 & 0.882 & 0.928 & 0.925 \\
\hline \multirow[t]{9}{*}{ Chemistry } & alk & 0.868 & 0.836 & 0.828 & 0.862 & 0.821 & 0.801 & 0.798 \\
\hline & cion & 0.842 & 0.815 & 0.885 & 0.810 & 0.858 & 0.889 & 0.906 \\
\hline & dic & 0.904 & 0.885 & 0.922 & 0.873 & 0.871 & 0.919 & 0.915 \\
\hline & nit & 0.844 & 0.813 & 0.872 & 0.847 & 0.848 & 0.832 & 0.908 \\
\hline & $\mathrm{ph}$ & 0.898 & 0.866 & 0.907 & 0.867 & 0.887 & 0.907 & 0.937 \\
\hline & pho & 0.904 & 0.874 & 0.895 & 0.853 & 0.879 & 0.893 & 0.929 \\
\hline & phos & 0.841 & 0.827 & 0.871 & 0.831 & 0.841 & 0.863 & 0.919 \\
\hline & sal & 0.896 & $\underline{0.901}$ & 0.924 & 0.910 & 0.892 & $\underline{0.941}$ & $\underline{0.945}$ \\
\hline & sil & 0.901 & 0.867 & 0.906 & 0.821 & 0.866 & 0.917 & 0.925 \\
\hline \multirow[t]{2}{*}{ Hydrodynamics } & regfl & 0.778 & 0.740 & $\underline{0.814}$ & 0.769 & 0.653 & 0.774 & $\underline{0.701}$ \\
\hline & vertfl & 0.616 & 0.614 & 0.667 & 0.630 & 0.597 & 0.650 & 0.609 \\
\hline \multirow[t]{3}{*}{ Oxygen } & aoxu & 0.811 & 0.773 & 0.779 & 0.758 & 0.812 & 0.799 & 0.850 \\
\hline & diso2 & 0.654 & 0.674 & 0.661 & 0.742 & 0.711 & 0.687 & 0.702 \\
\hline & poxs & 0.789 & 0.727 & 0.727 & 0.769 & 0.784 & 0.762 & 0.801 \\
\hline \multirow[t]{3}{*}{ Productivity } & modis & 0.767 & 0.674 & 0.683 & 0.752 & 0.682 & 0.676 & 0.831 \\
\hline & poc & $\underline{0.928}$ & $\underline{0.895}$ & $\underline{0.912}$ & $\underline{0.881}$ & $\underline{0.846}$ & $\underline{0.919}$ & $\underline{0.947}$ \\
\hline & vgpm & 0.758 & 0.688 & 0.766 & 0.716 & 0.729 & 0.784 & 0.870 \\
\hline Temperature & temp & 0.903 & 0.880 & 0.933 & 0.915 & 0.891 & 0.959 & 0.960 \\
\hline
\end{tabular}

If we examine the calcium carbonate saturation state for documented octocoral locations, less than $3 \%$ of octocoral observations were found in waters undersaturated $(\Omega<1)$ for calcite (Fig. 2). Less than $1 \%$ of Stolonifera observations were found in waters undersaturated with respect to calcite. This proportion was $6 \%$ for both Scleraxonia and Sessiliflorae. The proportions of records found in waters undersaturated with respect to aragonite were higher (Appendix S2b); 12\% of octocoral observations were undersaturated $(\Omega<1)$. This reflects the shallower saturation horizon for aragonite compared to calcite. For specific suborders, $15-20 \%$ of Scleraxonia, Sessiliflorae and Calcaxonia observations were below the aragonite saturation horizon, whist the other suborders are in the range $5-7 \%$. However, there was a substantial difference between the results using the alternate calcite saturation state layers. The data based on Orr et al. (2005) places 10\% of octocorals in areas of undersaturated waters with respect to calcite and reflects differences between the creation of the two datasets. Davies \& Guinotte (2011) utilized Orr et al. (2005) data for modelling scleractinians despite drawbacks in the extent of the data. We chose to use Steinacher et al. (2009) given the larger extent and better fit with the octocoral data used in this study. In addition, many of the specimens showing conflicting saturation states are found in the waters off the Aleutian Islands, an area with high octocoral diversity and abundance and a relatively shallow calcite saturation horizon (c. 260-440 m based on Orr et al., 2005). We note that the coral presence dataset was biased towards shallower areas, which are more likely to have higher calcium carbonate saturation states. Appendix S2c provides a depth distribution breakdown for all suborders demonstrating a pattern of lower sampling and lower saturation state at greater depth. It is difficult to gauge the true extent of the depth-sampling bias, particularly in a global scale analysis, and certainly some octocorals thrive in deep waters with very low calcium carbonate saturation states.

Increasing atmospheric $\mathrm{CO}_{2}$ levels directly leads to ocean acidification and a shallowing of both the aragonite and calcite 


\section{Yesson et al.}

Table 4 Model evaluation statistics for maximum entropy (Maxent) models of global distribution of deep-sea octocorals based on the seven selected variables. Thresholds are based on the maximum sensitivity plus sensitivity of the test data set.

\begin{tabular}{|c|c|c|c|c|c|c|c|}
\hline Statistic & Alcyoniina & Calcaxonia & Holaxonia & Scleraxonia & Sessiliflorae & Stolonifera & Subselliflorae \\
\hline \multicolumn{8}{|l|}{ Evaluation } \\
\hline Test AUC & 0.967 & 0.954 & 0.971 & 0.960 & 0.945 & 0.981 & 0.975 \\
\hline Test gain & 2.516 & 2.095 & 2.810 & 2.500 & 2.394 & 3.335 & 3.183 \\
\hline Entropy & 7.498 & 7.979 & 7.426 & 7.580 & 7.966 & 6.937 & 6.860 \\
\hline \multicolumn{8}{|l|}{ Threshold } \\
\hline Logistic value & 0.270 & 0.300 & 0.461 & 0.352 & 0.318 & 0.263 & 0.144 \\
\hline Test omission & 0.076 & 0.087 & 0.113 & 0.098 & 0.122 & 0.088 & 0.059 \\
\hline Area present & 0.100 & 0.129 & 0.042 & 0.075 & 0.115 & 0.055 & 0.079 \\
\hline \multicolumn{8}{|l|}{ Contribution (\%) } \\
\hline Oxygen (aoxu) & 1.0 & 1.0 & 1.7 & 4.4 & 3.6 & 1.6 & 2.0 \\
\hline$\Omega$ Calcite (calc) & 72.8 & 77.8 & 47.3 & 46.2 & 22.6 & 43.9 & 25.0 \\
\hline Productivity (poc) & 6.9 & 1.7 & 1.1 & 0.8 & 10.6 & 1.4 & 20.0 \\
\hline Current (regfl) & 1.8 & 0.4 & 0.5 & 0.9 & 0.8 & 4.9 & 0.6 \\
\hline (Sal)inity & 10.3 & 2.4 & 2.0 & 2.2 & 21.6 & 5.5 & 2.0 \\
\hline Slope $($ slo100 km) & 6.0 & 13.5 & 10.6 & 14.7 & 11.0 & 7.1 & 5.6 \\
\hline (Temp)erature & 1.1 & 3.2 & 36.7 & 30.8 & 29.8 & 35.5 & 44.7 \\
\hline
\end{tabular}

saturation horizons (Feely et al., 2004). Some regions of the world ocean (e.g. the Weddell Sea) are projected to become undersaturated with respect to aragonite and calcite across the entire water column by the year 2100 (Orr et al., 2005). As a result, large areas of octocoral habitat (both predicted and documented) that are presently located in saturated waters will experience undersaturated conditions within this century (Orr et al., 2005; Guinotte et al., 2006). The impact of reduced calcium carbonate saturation states on octocoral health is currently uncertain as no high $\mathrm{CO}_{2}$ laboratory experiments have been performed on cold-water octocorals.

Topographic information derived from bathymetric data has been used in habitat suitability modelling (Wilson et al., 2007; Woodby et al., 2009). Topography influences sedimentation, current flow and food supply (Davies et al., 2009). In this study we found the average slope based on a surrounding $100 \mathrm{~km}$ radius to be the most predictive topographic variable, consistently outperforming the more localized slope and ruggedness measures. The finest scale measures of slope and ruggedness presented here are directly derived from the bathymetry data and are at an approximate scale of $1 \mathrm{~km}$. This resolution is not sufficiently detailed to reveal local features that are located wholly within one grid cell.

Previous studies have shown hydrodynamics to be important factors determining octocoral distribution on sections of the continental shelf of North America (Bryan \& Metaxas, 2007). The regional flow variable was the highest weighted marginality factor for four of seven ENFA models, demonstrating a consistent differentiation between the regional flow profile of octocoral locations compared with the global ocean mean. Although the data suggest that octocorals dwell in areas of stronger current than the global average, this does not translate into predictive power for the habitat suitability models. In this study the single-layer models based on hydrodynamics performed the worst of all variables in terms of predictive power. This may be a scale issue, as the global- scale current layers do not contain detail of locally varying factors, such as currents influenced by topography, which are important for corals (Genin et al., 1986; Tittensor et al., 2009).

The correlation of habitat suitability maps presented in Table 5 demonstrates the similarity of niches for all suborders (mean $I=0.79$ ). The lowest correlation between any pair of suborders was for the sister suborders of the soft sediment specialists Pennatulacea (seapens): Sessiliflorae and Subselliflorae $(I=0.71)$. These two groups are structurally different with respect to polyp morphology and distribution and this could be interpreted as evidence of niche separation between the taxa. The greater extent of suitability for Sessiliflorae is apparent in the Atlantic (Fig. 1), where large areas of deeper water are shown to be suitable, which is in contrast to other suborders that are more focused on the high relief features of continental margins and major ridges. Some species of Sessiliflorae have adapted to life in abyssal waters by evolving macrophagy as a feeding strategy (e.g. Umbellula). The Calcaxonia have the widest habitat suitability of all the suborders, approximately $12.9 \%$ of global ocean area is suitable habitat (Table 4). This area is three times greater than the total area suitable for Holaxonia. However, these numbers are dependent on the choice of threshold selection and alternative thresholds could produce substantial differences in total area (Liu et al., 2005). Also we note that these areas are likely to be optimistic predictions of actual distributions as they are estimates of the potential rather than the realized niche.

\section{Sampling bias}

The 12,508 samples of octocorals represent the most extensive global database of cold-water corals yet produced, including samples dating from the 1880s through to the present day. The data are inevitably biased, due to geographically and vertically heterogeneous sampling effort and data availability. We 
Alcyoniina

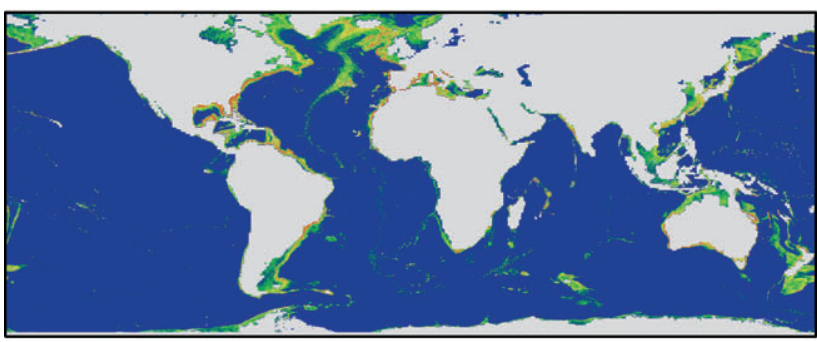

Holaxonia

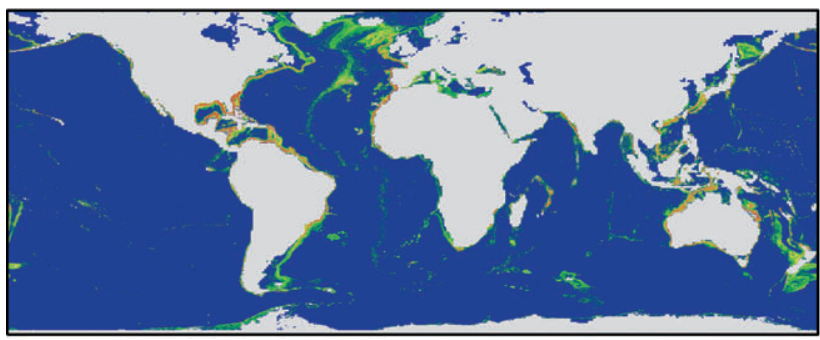

Sessiliflorae

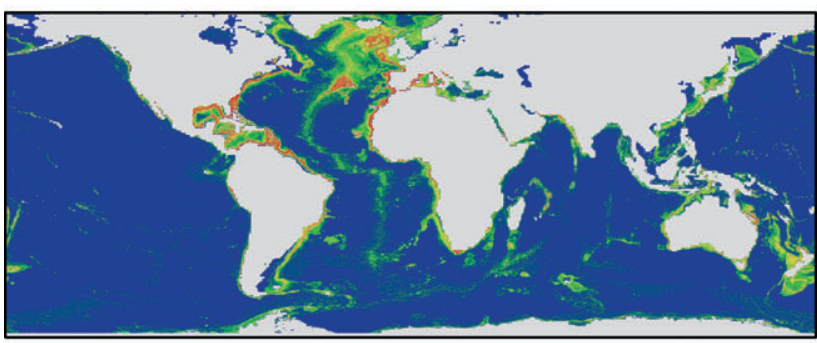

Subselliflorae
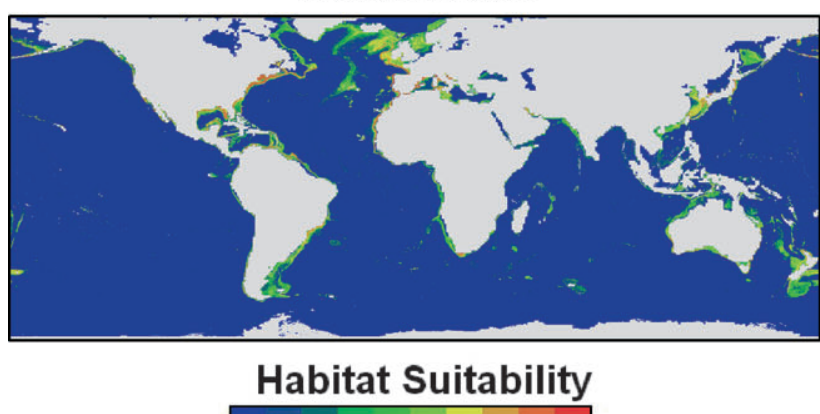

$\begin{array}{lllll}0.1 & 0.3 & 0.5 & 0.7 & 0.9\end{array}$
Calcaxonia

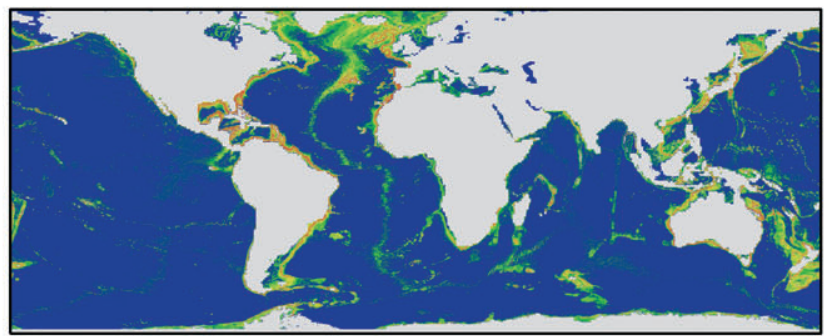

Scleraxonia

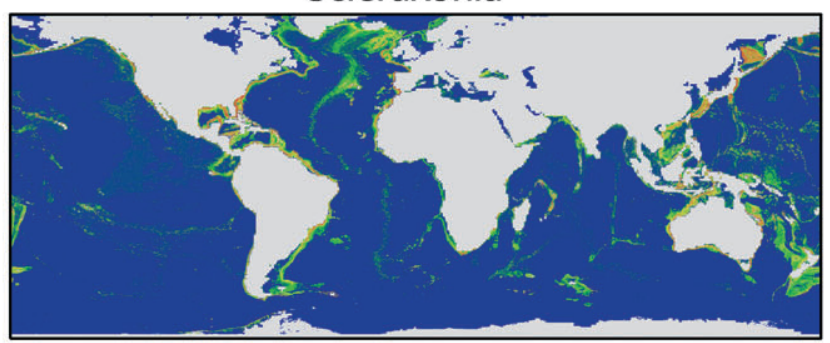

Stolonifera

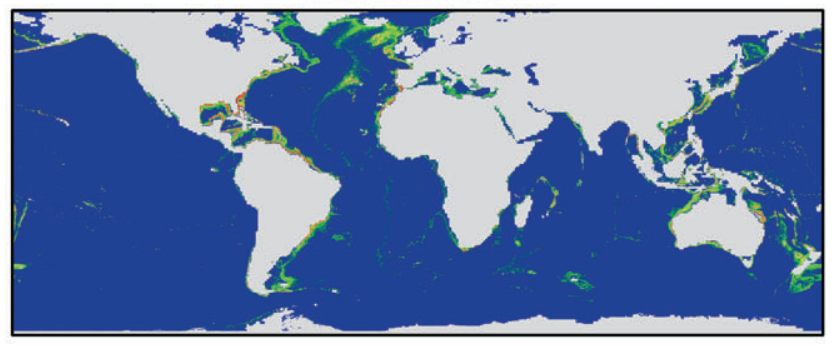

Octocoral consensus

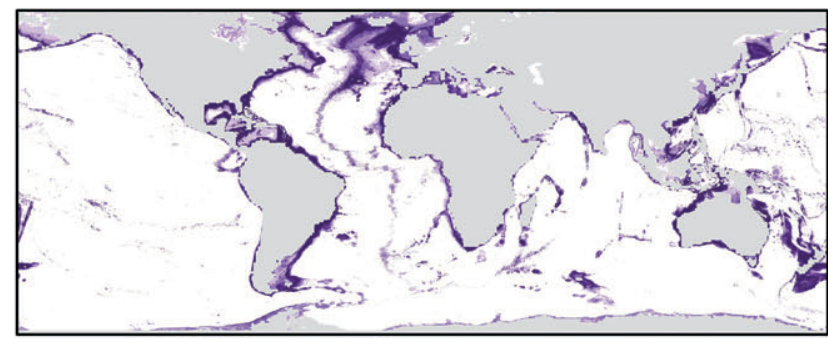

Number of suborders

Figure 3 Global maps showing habitat suitability for deep-sea octocorals. Suborder maps show logistic scores ranging from red = $1=$ high suitability, to dark blue $=0=$ low suitability. The consensus map displays a count of the number of suborders predicted present at each location (dark purple $=$ all seven suborders, white $=0$ suborders). GIS layers available at http://doi.pangaea.de/10.1594/PANGAEA.775081

consider that the continental shelves of the North Atlantic and Pacific North America and Hawaii are relatively well sampled in comparison to most other areas, particularly in contrast to the high seas and much of the South Pacific and Indian oceans. However, as long as the data span the entire environmental envelope of each suborder and assuming a similar environmental response between regions for octocorals, there should be little or no effect of the bias on the habitat suitability models. This is confirmed by the test for regional bias, which showed that removing heavily sampled areas from the analysis produced similar results. Other biases may influence the model, such as the area differences of the pixels of the environmental grid, or other sampling issues, such as depth bias.

Octocorals have been reported down to depths of $6620 \mathrm{~m}$ (Roberts et al., 2009), but more than $85 \%$ of the samples are reported from depths shallower than $3000 \mathrm{~m}$. The deep sea is difficult and expensive to sample, and undersampling of 

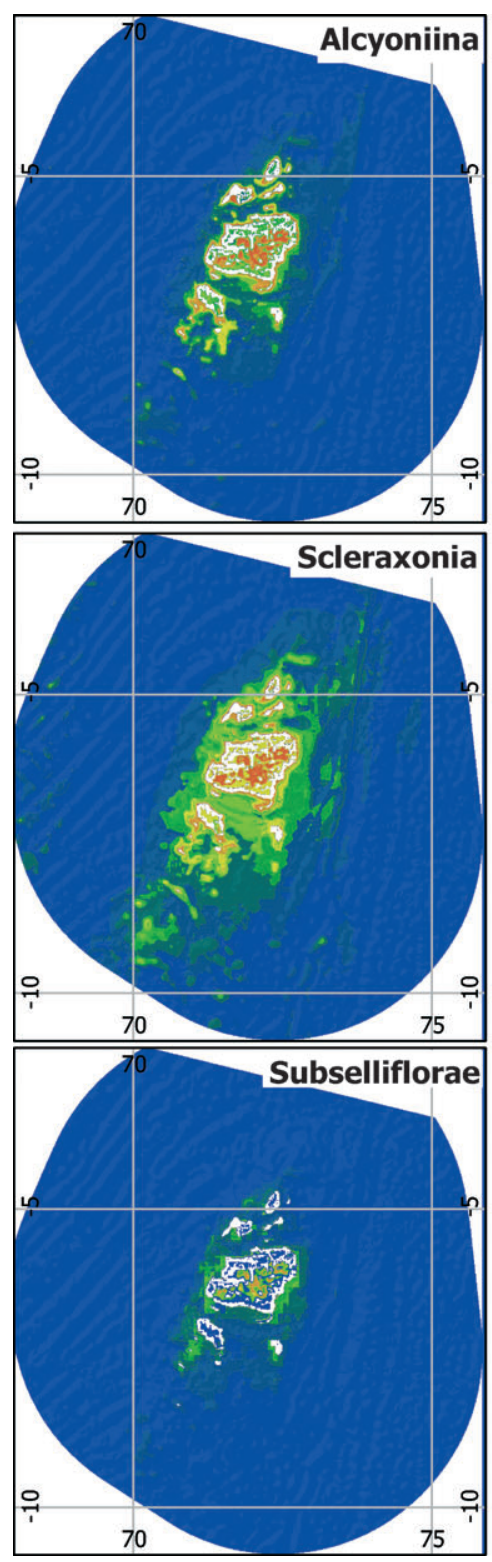
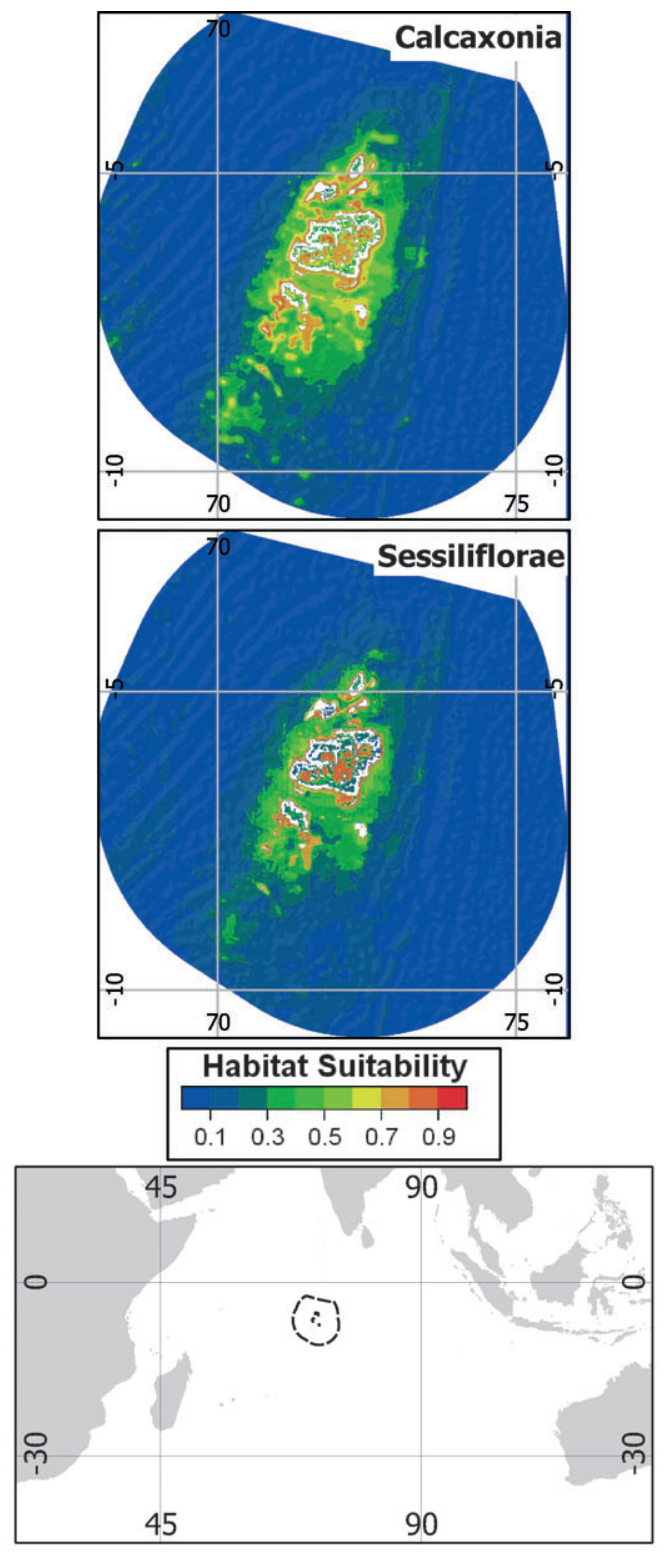

Figure 4 Habitat suitability for deep-sea octocorals within the British Indian Ocean Territory exclusive economic zone (EEZ). The dashed line delimits the EEZ, recently declared a Marine Protected Area by the British government. Red areas have high suitability, blue areas have low suitability. The inset regional map shows the extent of the zoomed region.

Table 5 Similarity of the Maxent habitat suitability maps between taxa of deep-sea octocorals globally. The upper triangle is the $I$ statistic (Warren et al., 2008). Bold indicates the maximum value, italic indicates the minimum value.

\begin{tabular}{|c|c|c|c|c|c|c|c|}
\hline Taxa & Alcyoniina & Calcaxonia & Holaxonia & Scleraxonia & Sessiliflorae & Stolonifera & Subselliflorae \\
\hline Alcyoniina & - & 0.84 & 0.85 & 0.76 & 0.79 & 0.81 & 0.78 \\
\hline Calcaxonia & & - & 0.87 & 0.80 & 0.86 & 0.76 & 0.72 \\
\hline Holaxonia & & & - & 0.82 & 0.82 & 0.83 & 0.78 \\
\hline Scleraxonia & & & & - & 0.74 & 0.79 & 0.74 \\
\hline Sessiliflorae & & & & & - & 0.72 & 0.71 \\
\hline Stolonifera & & & & & & - & 0.83 \\
\hline Subselliflorae & & & & & & & - \\
\hline
\end{tabular}


deep-sea habitats is always likely to be an issue for these types of analyses. The models accounting for depth bias had AUC scores significantly worse than those without depth-bias correction (AUC values range from 0.857 to $0.923, P<0.001$ for all models). This is the opposite to the pattern reported by Phillips et al. (2009), who found an improvement of AUC for bias-corrected models in areas with known sampling bias and used this improvement of model performance to justify their bias correction. For effective correction the bias must be well understood so that background data can be selected with the same bias as the specimen observations. Selecting background data to match the variable (i.e. depth) distribution profiles of occurrence data carries the underlying assumption that the observed profile is indicative of the sampling bias and is not indicative of any habitat preference. This assumption is incorrect for our data. Almost certainly we have both some level of sampling bias and a depth-based habitat preference and the latter confounds the former. At present we are unable to quantify the true extent of depth-based sampling bias relative
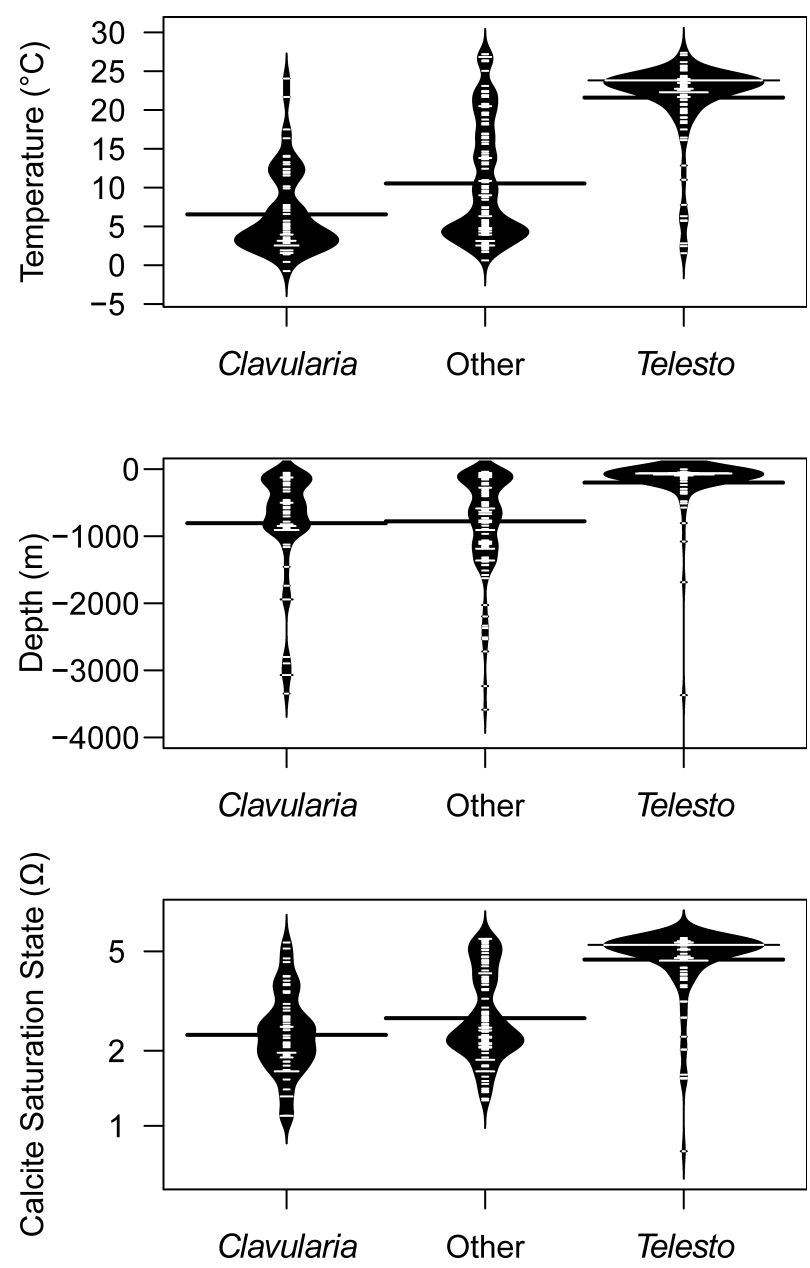

Figure 5 Frequency distribution of selected variables within suborder Stolonifera. The profiles for the two most sampled genera (Clavularia and Telesto) account for the bimodal frequency distribution seen in Fig. 2. The calcite saturation state is based on Steinacher et al. (2009). to the habitat preference and cannot justify employing a model correction that reduces model performance.

The models reported in this study are developed at the suborder level, rather than the species level commonly used in habitat suitability studies. The resulting models are likely to describe an artificially wide niche that encompasses the disparate habitat requirements of many species along with intermediate habitats that may prove unsuitable for any individual taxon. The potential problem of multi-taxon profiling is most evident for the Stolonifera, for which the temperature, calcite and salinity profiles show a bimodal distribution (Fig. 2). Many habitat suitability algorithms underperform when modelling taxa with bimodal distribution patterns (Sangermano \& Eastman, 2007). Breaking down the taxonomy of this suborder reveals a generic pattern underlying the bimodal distribution, with the two genera with greastest representation (Telesto and Clavularia) exhibiting divergent depth profiles (Fig. 5). However, the difficulties associated with octocoral taxonomy mean that generic identifications are not reliable, and the suborder level is at present the highest possible taxonomic resolution that can be used for global habitat suitability models.

\section{CONCLUSIONS}

Temperature, salinity, broad scale slope, productivity and oxygen levels were identified as key factors in the distribution of these corals. The calcite saturation state was found to be the key variable limiting distribution, with perhaps as few as 3\% of octocorals found in areas undersaturated for calcite, although this may be higher due to the depth-based sampling bias and dependent on source carbonate chemistry data. We estimate that approximately $3.5 \%$ of the global ocean is suitable for all seven suborders of octocorals and perhaps $17 \%$ is suitable for at least one suborder. The northern Atlantic and the coastal continental shelves of the Pacific Ocean are areas of high octocoral suitability. Other areas yet to be extensively surveyed, such as the British Indian Ocean Territory and smaller topographic features, including many seamounts in the high seas, were shown to contain potentially suitable habitat. Given the difficulty and expense of sampling the deep sea, it is likely that habitat suitability models will play an ever more important role in predicting the distributions of deep-sea fauna. We have provided results for models of seven octocoral suborders; these could be used to help guide management and conservation of this diverse group of cold-water corals.

\section{ACKNOWLEDGEMENTS}

We thank the European Union for the funding from the European Community's Seventh Framework Programme (FP7/2007-2013) under grant agreement number 213144, The CoralFISH Project. Support was also provided for this study by the International Union for Conservation of Nature (IUCN) project Cold-Water Coral Modeling and the Interactions of Ocean Acidification (Project No. 77059-000). The 
CenSeam and FMAP programs of the Census of Marine Life also contributed especially in the initial coral data gathering and modelling work. Michelle Taylor was funded by the Natural Environment Research Council (CASE Studentship NA/F00785X/1). The Marine Conservation Institute would like to thank the following foundations, organizations and individuals for their support: Arcadia, Sally Brown, Curtis and Edith Munson and Henry Foundations, Jonathan Edwards, Ben and Ruth Hammett, Herbert W. Hoover Foundation, International Union for the Conservation of Nature, J.M. Kaplan Fund, Naomi and Nehemiah Cohen Foundation, Oak Foundation, Pew Charitable Trusts, Richard and Rhoda Goldman Fund, and the Tiffany \& Co. Foundation. We also thank the editor and anonymous referees for their constructive comments and suggestions.

\section{REFERENCES}

Althaus, F., Williams, A., Schlacher, T., Kloser, R., Green, M., Barker, B., Bax, N., Brodie, P. \& Schlacher-Hoenlinger, M. (2009) Impacts of bottom trawling on deep-coral ecosystems of seamounts are long-lasting. Marine Ecology Progress Series, 397, 279-294.

Auster, P., Gjerde, K., Heupel, E., Watling, L., Grehan, A. \& Rogers, A. (2011) Definition and detection of vulnerable marine ecosystems on the high seas: problems with the "move-on" rule. ICES Journal of Marine Science, 68, 254264.

Bayer, F.M. \& Macintyre, I.G. (2001) The mineral component of the axis and holdfast of some gorgonacean octocorals (Coelenteratea: Anthozoa), with specieal reference to the family Gorgoniidae. Proceedings of the Biological Society of Washington, 114, 309-345.

Becker, J.J. \& Sandwell, D.T. (2008) Global estimates of seafloor slope from single-beam ship soundings. Journal of Geophysical Research, 113, C05028.

Becker, J.J., Sandwell, D.T., Smith, W.H.F., Braud, J., Binder, B., Depner, J., Fabre, D., Factor, J., Ingalls, S., Kim, S.-H., Ladner, R., Marks, K., Nelson, S., Pharaoh, A., Trimmer, R., von Rosenberg, J., Wallace, G. \& Weatherall, P. (2009) Global bathymetry and elevation data at 30 arc seconds resolution: SRTM30 PLUS. Marine Geodesy, 32, 355-371.

Behrenfeld, M. \& Falkowski, P. (1997) Photosynthetic rates derived from satellite-based chlorophyll concentration. Limnology and Oceanography, 42, 1-20.

Boyer, T.P., Levitus, S., Garcia, H.E., Locamini, R.A., Stephens, C. \& Antonov, J.I. (2005) Objective analyses of annual, seasonal, and monthly temperature and salinity for the World Ocean on a $0.25^{\circ}$ grid. International Journal of Climatology, 25, 931-945.

Bryan, T.L. \& Metaxas, A. (2006) Distribution of deep-water corals along the North American continental margins: relationships with environmental factors. Deep-Sea Research Part I - Oceanographic Research Papers, 53, 1865-1879.

Bryan, T.L. \& Metaxas, A. (2007) Predicting suitable habitat for deep-water gorgonian corals on the Atlantic and Pacific
Continental Margins of North America. Marine Ecology Progress Series, 330, 113-126.

Buhl-Mortensen, L. \& Mortensen, P. (2004) Symbiosis in deep-water corals. Symbiosis, 37, 33-61.

Cairns, S.D. (2007) Deep-water corals: an overview with special reference to diversity and distribution of deepwater Scleractinian corals. Bulletin of Marine Science, 81, 311-322.

Carroll, C. (2010) Role of climatic niche models in focal-species-based conservation planning: assessing potential effects of climate change on Northern Spotted Owl in the Pacific Northwest, USA. Biological Conservation, 143, 1432-1437.

Carton, J.A., Giese, B.S. \& Grodsky, S.A. (2005) Sea level rise and the warming of the oceans in the Simple Ocean Data Assimilation (SODA) ocean reanalysis. Journal of Geophysical Research, 110, 1955-1959.

Davies, A.J. \& Guinotte, J.M. (2011) Global habitat suitability for framework-forming cold-water corals. PLoS ONE, 6, e18483.

Davies, A.J., Wisshak, M., Orr, J.C. \& Roberts, J.M. (2008) Predicting suitable habitat for the cold-water coral Lophelia pertusa (Scleractinia). Deep-Sea Research Part I - Oceanographic Research Papers, 55, 1048-1062.

Davies, A.J., Duineveld, G.C.A., Lavaleye, M.S.S., Bergman, M.J.N., Van Haren, H. \& Roberts, J.M. (2009) Downwelling and deep-water bottom currents as food supply mechanisms to the cold-water coral Lophelia pertusa (Scleractinia) at the Mingulay Reef complex. Limnology \& Oceanography, 54, 620-629.

DeLong, E.R., DeLong, D.M. \& Clarke-Pearson, D.L. (1988) Comparing the areas under two or more correlated receiver operating characteristic curves: a nonparametric approach. Biometrics, 44, 837-845.

Dolan, M.F.J., Grehan, A.J., Guinan, J.C. \& Brown, C. (2008) Modelling the local distribution of cold-water corals in relation to bathymetric variables: adding spatial context to deep-sea video data. Deep-Sea Research Part I - Oceanographic Research Papers, 55, 1564-1579.

Edinger, E., Wareham, V. \& Haedrich, R. (2007) Patterns of groundfish diversity and abundance in relation to deep-sea coral distributions in Newfoundland and Labrador waters. Bulletin of Marine Science, 81, 101-122.

Etnoyer, P. \& Morgan, L.E. (2007) Predictive habitat model for deep gorgonians needs better resolution: comment on Bryan \& Metaxas (2007). Marine Ecology Progress Series, 339, 311312.

Feely, R.A., Sabine, C.L., Lee, K., Berelson, W., Kleypas, J., Fabry, V.J. \& Millero, F.J. (2004) Impact of anthropogenic $\mathrm{CO}_{2}$ on the $\mathrm{CaCO}_{3}$ system in the oceans. Science, 305, 362366.

Fielding, A.H. \& Bell, J.F. (1997) A review of methods for the assessment of prediction errors in conservation presence/ absence models. Environmental Conservation, 24, 38-49.

Freiwald, A., Fosså, J.H., Grehan, A., Koslow, J.A. \& Roberts, J.M. (2004) Cold-water coral reefs: out of sight - no longer out of mind. UNEP-WCMC, Cambridge. 
Garcia, H.E., Locarnini, R.A., Boyer, T.P. \& Antonov, J.I. (2006a). World ocean atlas 2005. Vol. 3: Dissolved oxygen, apparent oxygen utilization, and oxygen saturation (ed. by S. Levitus). NOAA, Washington, DC.

Garcia, H.E., Locarnini, R.A., Boyer, T.P. \& Antonov, J.I. (2006b). World ocean atlas 2005. Vol. 4: Nutrients (phosphate, nitrate, silicate) (ed. by S. Levitus). NOAA, Washington, DC.

Genin, A., Dayton, P.K., Lonsdale, P.F. \& Speiss, F.N. (1986) Corals on seamount peaks provide evidence of current acceleration over deep-sea topography. Nature, 322, 59-61.

Glover, A. \& Smith, C. (2003) The deep-sea floor ecosystem: current status and prospects of anthropogenic change by the year 2025. Environmental Conservation, 30, 219-241.

Guinotte, J.M., Orr, J., Cairns, S., Freiwald, A., Morgan, L. \& George, R. (2006) Will human-induced changes in seawater chemistry alter the distribution of deep-sea scleractinian corals? Frontiers in Ecology and the Environment, 4, 141-146.

Hall-Spencer, J.M., Allain, V. \& Fosså, J. (2002) Trawling damage to Northeast Atlantic ancient coral reefs. Proceedings of the Royal Society B: Biological Sciences., 269, 507-511.

Hirzel, A.H., Hausser, J., Chessel, D. \& Perrin, N. (2002) Ecological-niche factor analysis: how to compute habitatsuitability maps without absence data? Ecology, 83, 20272036.

Leverette, T.L. \& Metaxas, A. (2005) Predicting habitat for two species of deep-water coral on the Canadian Atlantic continental shelf and slope. Cold-water corals and ecosystems (ed. by A. Freiwald and J.M. Roberts), pp. 467-479. Springer-Verlag, Berlin.

Liu, C., Berry, P.M., Dawson, T.P. \& Pearson, R.G. (2005) Selecting thresholds of occurrence in the prediction of species distributions. Ecography, 28, 385-393.

Lutz, M.J., Caldeira, K., Dunbar, R.B. \& Behrenfeld, M.J. (2007) Seasonal rhythms of net primary production and particulate organic carbon flux to depth describe the efficiency of biological pump in the global ocean. Journal of Geophysical Research, 112, C10011.

Millero, F.J. (2006) Chemical oceanography, 3rd edn. Taylor and Francis Group, Boca Raton, FL.

Orr, J.C., Fabry, V.J., Aumont, O. et al. (2005) Anthropogenic ocean acidification over the twenty-first century and its impact on calcifying organisms. Nature, 437, 681-686.

Peterson, A.T., Papes, M. \& Eaton, M. (2007) Transferability and model evaluation in ecological niche modeling: a comparison of GARP and Maxent. Ecography, 30, 550-560.

Phillips, S.J. \& Dudík, M. (2008) Modeling of species distributions with Maxent: new extensions and a comprehensive evaluation. Ecography, 31, 161-175.

Phillips, S.J., Dudík, M., Elith, J., Graham, C.H., Lehmann, A., Leathwick, J. \& Ferrier, S. (2009) Sample selection bias and presence-only distribution models: implications for background and pseudo-absence data. Ecological Applications, 19, 181-197.

Roberts, J.M., Wheeler, A.J., Freiwald, A. \& Cairns, S.D. (2009) Cold-water corals. Cambridge University Press, Cambridge.
Rogers, A.D. \& Gianni, M. (2010) The implementation of UNGA resolutions 61/105 and 64/72 in the management of deep-sea fisheries on the high seas. Report prepared for the deep-sea conservation coalition. International Programme on the State of the Ocean, London.

Rogers, A.D., Taylor, M., Kemp, K., Yesson, C. \& Davies, A. (in press) The diseases of deep-water corals. Diseases of corals (ed. by C. Downs). CRC Press, London/New York.

Sangermano, F. \& Eastman, R. (2007) Linking GIS and ecology - the use of Mahalanobis typicalities to model species distribution. Memorias XI Conferencia Iberoamericana de Sistemas de Información Geográfica (ed. by G.D. Buzai), pp. 1-13. Sociedad Iberoamericana de Sistemas de Información Geográfica, Universidad Nacional de Luján, Buenos Aires.

Söffker, M., Sloman, K. \& Hall-Spencer, J.M. (2011) In situ observations of fish associated with coral reefs off Ireland. Deep Sea Research Part I: Oceanographic Research Papers, 58, 818-825.

Steinacher, M., Joos, F., Frölicher, T.L., Plattner, G.K. \& Doney, S.C. (2009) Imminent ocean acidification projected with the NCAR global coupled carbon cycle-climate model. Biogeosciences, 6, 515-533.

Stone, R. (2006) Coral habitat in the Aleutian Islands of Alaska: depth distribution, fine-scale species associations, and fisheries interactions. Coral Reefs, 25, 229-238.

Tittensor, D.P., Baco, A.R., Brewin, P.E., Clark, M.R., Consalvey, M., Hall-Spencer, J.M., Rowden, A.A., Schlacher, T., Stocks, K.I. \& Rogers, A.D. (2009) Predicting global habitat suitability for stony corals on seamounts. Journal of Biogeography, 36, 1111-1128.

Warren, D.L., Glor, R.E. \& Turelli, M. (2008) Environmental niche equivalency versus conservatism: quantitative approaches to niche evolution. Evolution, 62, 2868-2883.

Watling, L. \& Norse, E. (1998) Disturbance of the seabed by mobile fishing gear: a comparison to forest clearcutting. Conservation Biology, 12, 1180-1197.

Wilson, M.F.J., O'Connell, B., Brown, C., Guinan, J.C. \& Grehan, A.J. (2007) Multiscale terrain analysis of multibeam bathymetry data for habitat mapping on the continental slope. Marine Geodesy, 30, 3-35.

Woodby, D., Carlile, D. \& Hulbert, L. (2009) Predictive modeling of coral distribution in the Central Aleutian Islands, USA. Marine Ecology Progress Series, 397, 227-240.

\section{SUPPORTING INFORMATION}

Additional supporting information may be found in the online version of this article:

Appendix S1 Sources for the octocoral database.

Appendix S2 Correlation and frequency distribution of variables analysed.

Appendix S3 Details and projection of environmental niche factor analysis (ENFA) models.

As a service to our authors and readers, this journal provides supporting information supplied by the authors. Such 
materials are peer-reviewed and may be re-organized for online delivery, but are not copy-edited or typeset. Technical support issues arising from supporting information (other than missing files) should be addressed to the authors.
BIOSKETCH

Chris Yesson is a postdoctoral researcher investigating the distribution of deep-sea octocorals for the EU funded CoralFISH project. He is particularly interested in phyloclimatic modelling, the examination of ecological niches of closely related species from a phylogenetic perspective.

Author contributions: A.D.R., A.J.D., J.G. and D.P.T. conceived and planned the project; A.J.D. and J.G. produced and contributed environmental grids; M.L.T., A.D.R., D.P.T., A.B., J.M.H.S. and J.B. contributed substantially to octocoral database; C.Y. and D.P.T. designed experiments; C.Y. ran the experiments; all authors contributed to the writing.

Editor: Alistair Crame 